\title{
The Thirty-First Year Journey, the Journal of the Korean Academy of Child and Adolescent Psychiatry
}

\author{
Hee Jeong Yoo', Min-Hyeon Park², Jae Hyun Yoo ${ }^{3}$, Minha Hong ${ }^{4}$, and Geon Ho Bahn ${ }^{5}$ \\ ${ }^{1}$ Department of Psychiatry, Seoul National University Bundang Hospital, Seoul National University College of Medicine, Seongnam, Korea \\ ${ }^{2}$ Department of Psychiatry, Eunpyeong St. Mary's Hospital, College of Medicine, The Catholic University of Korea, Seoul, Korea \\ ${ }^{3}$ Department of Psychiatry, Seoul St. Mary's Hospital, College of Medicine, The Catholic University of Korea, Seoul, Korea \\ ${ }^{4}$ Department of Psychiatry, Myongji Hospital, Hanyang University College of Medicine, Goyang, Korea \\ ${ }^{5}$ Department of Psychiatry, Kyung Hee University School of Medicine, Seoul, Korea
}

\begin{abstract}
Objectives: The Journal of the Korean Academy of Child and Adolescent Psychiatry (JKACAP) has had a 31 year-long history, sharing research and reviews of children and adolescents' mental health to promote voluntary participation and communication of the members of this society. Here, we have reviewed the detailed history of the journal from the perspective of developmental progression of JKACAP and discussed the direction of further development.

Methods \& Results: We reviewed the journey of the journal by focusing on the effort it took to take the journal to a global standard, and discussed the future direction of progress of JKACAP, based on the opinions raised at the Editor-in-Chiefs' reunion.

Conclusion: JKACAP has just stepped on the path to globalization by being indexed in Emerging Sources Citation Index, PubMed Central, and Scopus. It is time to progress to another dimension, by acknowledging and overcoming more complicated issues, such as augmenting impact of the journal, expanding domains of interdisciplinary collaboration, and more global cooperation.
\end{abstract}

Key Words: Korean; Child; Adolescent; Psychiatry; Journal; Trajectory; Perspective.

Received: August 26, 2020 / Accepted: August 31, 2020

Address for correspondence: Geon Ho Bahn, Department of Psychiatry, Kyung Hee University School of Medicine, 23 Kyungheedae-ro, Dongdaemungu, Seoul 02447, Korea

Tel: +82-2-958-8542, Fax: +82-2-957-1997, E-mail: mompeian@khu.ac.kr

\section{INTRODUCTION}

Academic journals play an essential role in communicating and transferring knowledge to professionals in various fields. The developmental trajectories of the journals often coincide with the resources, necessities, and performance of academic research in the field. It is not an exception to the Journal of the Korean Academy of Child and Adolescent Psychiatry (JKACAP), indexed as Soa Chongsonyon Chongsin Uihak in PubMed Central (PMC).

The JKACAP was first published four years after the establishment of the Korean Academy of Child and Adolescent Psychiatry (KACAP), and has completed a journey of 31 years. Although the developmental stage of the journal was slow and tumultuous, with the expansion of human resources in the field of child and adolescent psychiatry in Korea, maturation of the child psychiatry fellowship program, and devotion of clinicians/researchers, it has stepped up to meet the global standards. It has been a long and winding journey with de-

This is an Open Access article distributed under the terms of the Creative Commons Attribution Non-Commercial License (https://creativecommons.org/licenses/by-nc/4.0) which permits unrestricted non-commercial use, distribution, and reproduction in any medium, provided the original work is properly cited. velopmental transitions.

Therefore, the editorial board came to a consensus that they should record the journey of JKACAP, and prepare for the opportunities and challenges in the future, to commemorate the journal's 31st anniversary. Here, we have reviewed the detailed history from the perspective of developmental progression of JKACAP, described the process of journal's globalization in terms of the effort it took to take the journal to a global standard, and discussed the future directions of progress of JKACAP, referring to the opinions of previous and current Editor-in-Chief's (EIC).

\section{PAST: HISTORICAL REVIEW OF JKACAP}

The Korean Child and Adolescent Psychiatry Research Society, established on March 20, 1983, changed to the official academic organization 'Korean Child and Adolescent Psychiatry Association' on July 17, 1985, and was registered as the 'Korean Academy of Child and Adolescent Psychiatry (KACAP)' on November 29, 1986. The official journal of KACAP was published in December 1990 (Fig. 1). The first EIC was Kang-E Michael Hong (1990-1994), followed by Soo Churl 


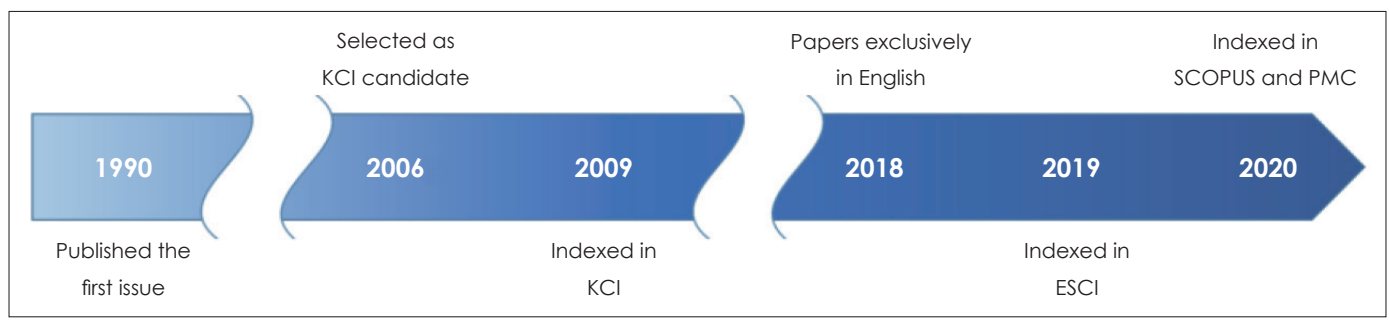

Fig. 1. Footsteps of the journal, representative of the Korean Academy of Child and Adolescent Psychiatry. KCl: Korea Citation Index, ESCl: Emerging Sources Citation Index, PMC: Pubmed Central.

Table 1. Historical retrospectives of the journal

\begin{tabular}{|c|c|c|c|c|c|}
\hline Period & Editor-in-chief & Issues/year & $\mathrm{IF}(\mathrm{KCl})$ & Main language & Indexing \\
\hline $1990-1994$ & Kang-E Michael Hong & 1 & & Korean* & \\
\hline 1995 & Soo Churl Cho & 1 & & Korean & \\
\hline $1996-2001$ & Soo Churl Cho & 2 & & Korean & \\
\hline 2002 & Soo Churl Cho & 1 & & Korean & \\
\hline $2003-2006$ & Dong Ho Song & 2 & & Korean & $\mathrm{KCl}$ candidate (2006) \\
\hline 2007 & Dong-Won Shin & 2 & & Korean & $\mathrm{KCl}$ candidate \\
\hline $2008^{*}$ & Dong-Won Shin & 3 & 0.32 & Korean & $\mathrm{KCl}$ candidate \\
\hline $2009^{*}$ & Dong-Won Shin & 3 & 0.51 & Korean & $\mathrm{KCl}$ accredited \\
\hline $2010^{*}$ & Jeong-Seop Lee & 3 & 0.24 & Korean & $\mathrm{KCl}$ accredited \\
\hline \multirow[t]{3}{*}{$2011-2013^{*}$} & Jeong-Seop Lee & 4 & $0.34(2011)$ & Korean & $\mathrm{KCl}$ accredited \\
\hline & & & $0.25(2012)$ & & \\
\hline & & & $0.31(2013)$ & & \\
\hline \multirow[t]{2}{*}{ 2014-2015* } & Soo Churl Cho & 4 & $0.47(2014)$ & Korean & $\mathrm{KCl}$ accredited \\
\hline & & & $0.42(2015)$ & & \\
\hline $2016^{*}$ & Geon Ho Bahn & 4 & 0.71 & Korean & $\mathrm{KCl}$ accredited \\
\hline $2017^{*}$ & Geon Ho Bahn & 4 & 0.73 & Korean/English & $\mathrm{KCl}$ accredited \\
\hline \multirow[t]{4}{*}{$2018^{*}-2020$} & Geon Ho Bahn & 4 & $0.69(2018)$ & English & $\mathrm{KCl}$ accredited \\
\hline & & & N/A (2019-2020) & & $\mathrm{ESCl}(2019 / 06-)$ \\
\hline & & & & & PMC (2020/06-) \\
\hline & & & & & SCOPUS (2020/04-) \\
\hline
\end{tabular}

*Korean language with English abstracts. IF: impact factor, KCl: Korea Citation Index, PMC: Pubmed Central

Cho (1995-2002, 2014-2015), Dong Ho Song (2003-2006), Dong-Won Shin (2007-2009), Jeong-Seop Lee (2009-2013), and Geon Ho Bahn (2016-2020) (Table 1).

Initially, JKACAP was published once a year, and since 2011, it has been publishing four issues a year (EIC Jeong-Seop Lee). In addition, the JKACAP became a candidate journal of Korea Citation Index (KCI), run by National Research Foundation of Korea, in 2006 (EIC Dong Ho Song), and was indexed as KCI accredited journal in 2009 (EIC Dong-Won Shin). Although the journal failed at the first screening to attain KCI accreditation, it passed the second screening and still continues to be a KCI-accredited journal. At the EICs' reunion on June 29, 2020 to celebrate the JKACAP's 31st anniversary, the EICs cited the important milestones of the journal during their respective tenures such as the increasing the number of publications per year and maintaining indexing in the KCI. Moreover, they all agreed that they had paid attention to the publications on time, and that the journal had gone through a virtuous cycle of development by encouraging article submission while developing child and adolescent psychiatric fellowship training program. The former EICs also shared the timely and wise tips that helped the journal achieve global standards.

The full name of the journal in English at its inception was the Korean Journal of Child and Adolescent Psychiatry, and changed to the Journal of the Korean Academy of Child and Adolescent Psychiatry from Vol. 17, No. 2 in 2006. After being indexed in $\mathrm{KCI}$, there were several discussions on ending the Korean version of JKACAP and re-publishing it as the English version for indexing in international portal systems such as PMC, Scopus, and Science Citation Index Expanded (SCIE). In January 2016, after EIC Geon Ho Bahn took office, indexing in the international portal system work began in earnest with the full agreement of the board members of KACAP. 
Despite $82.1 \%$ of the members from KACAP survey approving the indexing in SCIE [1], those who insisted on maintaining a Korean version of the journal were as high as $64.8 \%$; hence, the existing Korean version of JKACAP, without republishing as a new English journal, promoted the work of converting the papers exclusively in English with the same title, JKACAP.

As for the topic propensity of the articles published in JKACAP, the psychosocial issues had a high proportion since the beginning of publication, while pharmacotherapy and biological issues are still low in proportion (Table 2). The former EICs were positive about welcoming and expanding the submissions of experts and allied professionals such as mental health nurses, clinical psychologists, and doctors in other specialties. Since there are a lot of works in collaboration with experts in neighboring fields, it is possible to publish highquality articles, and they have also suggested inviting them as reviewers or appointing experts in neuroscience and psychology as editors. It is thought that by reflecting these opinions, it is possible to explore the diversity of the topic matter of JKACAP. The 5-year KCI impact factor (IF) of JKACAP is in the range of 0.24 (lowest in 2010)- 0.73 (highest in 2017) (statistics are available since 2008), is on an increasing trend, and has ranked 3rd among 17 journals under Psychiatry subclass in KCI [2].

In the network structure analysis of 251 articles by 564 participating authors published in JKACAP during 2005-2015, except 20 out of 564 had an academic network [3], and this intensive network configuration showed that there is a close academic interaction between authors, but it reflects the characteristics of a small-world network. This suggests the possibility that the majority of the authors who have published in JKACAP could be experts in Child And Adolescent Psychiatry, and hence, the research topics may have limited diversity (Table 3).

In line with EIC Bahn's attempt to bring JKACAP to global standards, an online submission system was established in 2016, a website of JKACAP was set in 2017, the printed version of the journal was ended, and an online open access journal was established. Among the four issues in 2017, the two were published in Korean, and other two in English. Since 2018, the all the four issues in a year have been published in English with a publication fee (\$300). Currently, there are 10 members in the editorial committee from Korea, three from the US, two from Japan, one from Indonesia, one from China, one from the Netherlands, and two from Singapore, and the number is expected to increase.

JKACAP was indexed in ESCI in June, 2019, listed on Scopus in April 2020, and indexed in PMC since June 2020.

\section{PRESENT: PATH TO GLOBALIZATION FOCUSED ON JKACAP AND ACTIVITIES OF TASK FORCE TEAM}

By publishing in an international journal, it is not only possible to influence the creation, spread, and circulation of aca-

Table 2. Categories of articles published on the Journal of the Korean Academy of Child and Adolescent Psychiatry from 1990 to 2019

\begin{tabular}{ccccr}
\hline Years & Psychosocial issues & Biological issues & Pharmacotherapy & Subtotal \\
\hline $1990-1995$ & 50 & 8 & 4 & 62 \\
$1996-2007$ & 179 & 22 & 6 & 207 \\
$2008-2010$ & 33 & 7 & 3 & 43 \\
$2011-2017$ & 145 & 15 & 16 & 176 \\
$2018-2019$ & 37 & 4 & 1 & 42 \\
Total (\%) & $444(83.8)$ & $56(10.5)$ & $30(5.7)$ & $530(100.0)$ \\
\hline
\end{tabular}

Table 3. Types of articles published on the Journal of the Korean Academy of Child and Adolescent Psychiatry from 1990 to 2019

\begin{tabular}{lcccccc}
\hline \multicolumn{1}{c}{ Types } & $1991-1995$ & $1996-2000$ & $2001-2005$ & $2006-2010$ & $2011-2015$ & $2016-2019$ (4 years) \\
\hline Review & 2 & 1 & 10 & 22 & 25 & 14 \\
Original article & 43 & 111 & 69 & 60 & 111 & 69 \\
Short communication & 9 & 6 & 0 & 0 & 0 & 0 \\
Book review & 5 & 7 & 0 & 0 & 0 & 4 \\
Special article & 32 & 0 & 19 & 0 & 3 & 2 \\
Case report & 1 & 9 & 3 & 0 & 3 & 0 \\
Journal Review & 0 & 14 & 1 & 0 & 0 \\
Special review & 0 & 0 & 5 & 475 & 790 & 479 \\
Authors & 215 & 427 & 317 & & & 0 \\
\hline
\end{tabular}


demic information more actively and broadly [4], but also to enhance the status of the organization that issues the journal. For the purpose of globalization and brand enhancement, a Task Force was launched with leader Prof. Park Min-Hyeon and member Prof. Yoo Jae Hyun in April 2019. As the first step of journal globalization, only English papers were published since 2018, and the publishing system was overhauled according to the International Standards for Digital Publishing [5]. Second, the submission guidelines were revised to fulfill the recommendations of the International Committee of Medical Journal Editors (ICMJE) [6], and electronic submission systems and English language websites were also revised accordingly. In addition, foreign scholars and scholars in various areas such as statistics and ethics were invited to serve as editorial board members. As a result, JKACAP was listed on ESCI (applied December 2017, selected June 2019), Scopus (applied March 2020, selected April 2020) and PMC (applied January 2020, selected June 2020) sequentially without a single rejection.

\section{International standards for digital publishing}

Journal article tag suite (JATS) XML (eXtensible Markup Language), PubReader, epub, PDF, digital object identifier (DOI), CrossMark (Check for update), Fundref (Funder registry), Text and Data Mining (TDM), open researcher and contributor ID (ORCID) are representative International Standards for Digital Publishing related to scholarly articles [5].

JATS XML was designated by the National Center for Biotechnology Information (NCBI) of the National Library of Medicine (NLM) in the US for the purpose of providing a common format in which publishers and archives could exchange journal content. JATS XML has been positioned as the International Organization for Standardization (ISO) standard in the digital publishing area since 2013 [7]. XML is very unique such that it shows not only the form of an electronic document but also the properties of an electronic document using a 'tag' that users can discern, for example, where the title, references, and discussion are [8]. JATS XML also has the advantage that it can be easily converted to various International Standards for Digital Publishing such as PubReader, epub, DOI, CrossMark, Fundref, TDM and ORCID. DOI is an intrinsic set of letters and symbols used to identify an online document such as a journal article or an eBook. As the DOI is unique, it will help the reader to easily locate a document on the web from the citation.

The following are the terms related to the International Standards for Digital Publishing or global indexing.

\section{International Committee of Medical Journal Editors}

The ICMJE is a working group of medical journal editors.
The ICMJE participants meet annually and fund their own work on the recommendations for the conduct, reporting, editing and publication of scholarly work in medical journals. The ICMJE recommendations were initially published in 1978 and have been continuously revised [6].

\section{Major global indexes}

\section{Web of science}

Web of science is a website that provides subscription-based access to multiple databases including SCIE, Social Sciences Citation Index (SSCI), and Art \& Humanities Citation Index (A \& HCI) and is currently maintained by Clarivate Analytics (since 2017, previously the Intellectual Property and Science business of Thomson Reuters). The difference between SCI and SCIE is that SCI was selected as a print or CD-ROM version before web-service and SCIE was selected after webbased service became available. In January 2020, SCI and SCIE were integrated into SCIE [9]. The Emerging Sources Citation Index (ESCI) was launched in 2015 as a new database in Web of Science. Generally, the selection process is considered the first step in applying to other Web of Science indexes such as SCI, SSCI, and A \& HCI [10].

\section{Scopus}

Scopus was launched in 2004 by Elsevier, a world-famous Dutch publishing company. Scopus currently covers nearly 36,377 titles. Scopus gives four types of quality measures: $\mathrm{h}$ Index, CiteScore, SCImago Journal Rank (SJR), and Source Normalized Impact per Paper (SNIP) [11].

\section{PubMed and PubMed central}

PubMed and PMC are digital repositories developed by the NCBI. PubMed is a searchable database of biomedical citations and abstracts and PMC is free digital repository to allow open access to full-text articles [12].

\section{Current status of JKACAP}

To explore the current status of JKACAP multi-directionally, we simultaneously examined the status of other Korean medical and other psychiatry journals. KCI by National Research Foundation of Korea covers all scholarly articles published in Korea. As of August 11, 2020, 2,192 journals were indexed as accredited in the $\mathrm{KCI}$, and 324 were registered as candidates and 3,288, nonregistered journals [2].

Internationally, among all biomedical journals, 17,000 are indexed in Scopus and 2,687 are indexed in PMC. Among Korean medical journals, 47 were indexed in SCI, SSCI or A \& $\mathrm{HCI}$ as of January 2020, and 104 were indexed in Scopus as of September 2019. Among Korean psychiatry journals, JKA- 
CAP was indexed third in PMC and Scopus, behind Psychiatry Investigation (www.psychiatryinvestigation.org) and Clinical Psychopharmacology and Neuroscience (www.cpn.or.kr).

Currently, JKACAP is issued quarterly (1st of January, April, July, and October). In 2019, a total of 39 manuscripts were submitted and the rejection rate was $35.90 \%$. From 2017, many papers were submitted from abroad including from China, Hong Kong, Japan, India, and Turkey. In 2019, the reading factor (RF, defined as the ratio between the number of electronic consultations of an individual journal and the mean number of electronic consultations of all the Korean journals studied) by National Digital Science Library (NDSL) was 2.25, indicating that JKACAP was read 2.25 times more compared to other Korean journals. With a RF of 2.25, the journal ranks third among all Korean psychiatry journals [13].

Presently, JKACAP is progressing favorably toward becoming a prestigious international journal. This splendid achievement might be the result of the dedication of the predecessors who have maintained JKACAP for more than 30 years, including the current EIC, Geon Ho Bahn, who has been at the head position for long and has spearheaded the remarkable progress of JKACAP. In addition, the success of JKACAP can be attributed to the authors who submitted high-quality manuscripts, reviewers who served a vital role with passion even without rewards, and the readers who have read the journal with great interest and sent their sincere advice.

\section{TOWARD FUTURE: PATH TO THE BEST PRACTICES FOR JKACAP}

\section{Learning from high impact international journals}

During its long journey, JKACAP has been pursuing continuous transformation to enhance scientific quality and popularity. In the future, JKACAP should not only capture important issues related to children and adolescent mental health, but also continue to make every effort to improve the size of readership and the credibility of the journal.

Therefore, it is meaningful to review the historical events of high impact journals such as Journal of the American Academy of Child and Adolescent Psychiatry (JAACAP) and European Child and Adolescent Psychiatry (ECAP) during past decades. First, JAACAP has a long history of about 60 years [14]. The American Academy of Child Psychiatry founded its own journal in 1961. Initially, it published four issues per year. In the 1980s, JAACAP converted to a bi-monthly publication, and started to bring out Practice Parameters which resulted from empirical studies. JAACAP finally expanded to monthly publications in 1995. Along with the quantitative growth of journal articles, the online accessibility of JAACAP has considerably improved since the opening of separate jour- nal websites in 2009. In addition to the extensive changes in its appearance, the journal's acceptance rate dropped to below 30 percent [15]. Although the number of all citable articles was slightly reduced, these major changes have contributed to improving the both quantity and quality of publications. Since 2011, the JCR impact factor of JAACAP has exceeded 6 points and it became a leading journal in the field of child and adolescent psychiatry. JAACAP also runs its own extension, JAACAP Connect, to encourage brief communications from practitioners and trainees about contemporary topics of child and adolescent mental health.

On the other hand, ECAP aimed to promote the growth of empirically based clinical child and adolescent psychiatry throughout Europe at its inception [16]. It was the official journal of European Society for Child and Adolescent Psychiatry (ESCAP), started with four issues per year in 1992. Although ECAP expected that the publications or materials would be derived from European population, it also welcomed international studies. Between the years 2003 and 2007, ECAPESCAP collaboration was cut. However, ECAP was soon redesignated as the official journal of ESCAP in 2011. Since then, its impact factor has grown from 1.651 in 2009 to 3.699 in 2012. In particular, the rapid growth in citations is also largely attributed to the increase in international collaboration articles, from $31.31 \%$ in 2009 to $43.21 \%$ in 2019 [17]. The progress of both journals clearly shows the importance of enhancing quantity and quality of publications, managing latest topics, and participating in the international workforce.

\section{Suggestions from former EICs and editorial board members}

To reach the status of major journals such as JAACAP and ECAP in the near future, the former EICs and editorial board members suggested the following directions at the EIC reunion on June 29, 2020.

First, to improve the quality and quantity of journals, JKACAP may well cover cutting-edge topics (i.e., COVID-19 and social distancing on children's mental health) and emerging global issues (i.e., big data science, accelerated deglobalization in a hyperconnected world, and the incredible influence of BTS on adolescents around the globe) which meet readers' imminent interests. This might help attract the attention of international readers, and enhance the reputation of the journal with an additional sense of immediacy and relevance.

Second, JKACAP needs to recruit more experts in related fields as scientific reviewers and editorial board members. Allied professionals such as clinical psychologists, social workers, and play therapists also play an important role in the diagnosis, treatment, and rehabilitation process of children who suffer from mental illnesses. They can provide diverse perspec- 
tives on approaching patients' adversity in terms of clinical research. In addition, it would be necessary to cooperate with neuroscience researchers, statistics experts, and big data scientists to verify the validity and reliability of scientific articles with novel and complex methods.

Third, to establish global renown, JKACAP may well facilitate collaboration with international organizations. In order to promote global cooperation in stages, JKACAP may consider inviting international experts as reviewers and editorial board members first. As the next step, the journal will try to establish cooperative relationships with international expert societies of child and adolescent mental health such as Asian Society of Child and Adolescent Psychiatry and Allied Professions (ASCAPAP). The contribution of international researchers can advocate key mental health concerns arising locally as well as globally, and promote joint research from international teams with shared interests.

\section{CONCLUSION}

In a journey of 31 years, JKACAP stepped into a global realm by being indexed in ESCI, PMC, and Scopus. It is time to progress to another dimension, by acknowledging and overcoming more complicated issues, such as augmenting impact of the journal, expanding domains of interdisciplinary collaboration, and more global cooperation. As it was at the beginning, now, and in the future, JKACAP pursues to ensure the well-being and happiness of mentally challenged children and their families.

\section{Acknowledgments}

Editorial committee would like to express the deepest gratitude to the previous members of the committee and reviewers for their contribution to the development of this journal. Thanks to people of Raum and Inforang helping to design the website of the journal based on readers' convenience.

\section{Conflicts of Interest}

The authors have no potential conflicts of interest to disclose.

\section{Author Contributions}

Conceptualization: all authors. Data curation: Min-Hyeon Park, Jae Hyun Yoo, Minha Hong. Formal analysis: Minha Hong. Project administration: Hee Jeong Yoo, Geon Ho Bahn. Software: Min-Hyeon Park, Jae Hyun Yoo. Supervision: Geon Ho Bahn. Validation: Hee Jeong Yoo. Visualization: Minha Hong. Writing_original draft: Min-Hyeon Park, Jae Hyun Yoo, Minha Hong. Writing—review \& editing: Hee Jeong Yoo, Geon Ho Bahn.

\section{ORCID iDs}

Hee Jeong Yoo https://orcid.org/0000-0003-0521-2718

Min-Hyeon Park https://orcid.org/0000-0002-1731-1388

Jae Hyun Yoo https://orcid.org/0000-0002-2579-9993

Minha Hong https://orcid.org/0000-0003-4924-1107

Geon Ho Bahn https://orcid.org/0000-0002-3550-0422

\section{REFERENCES}

1) Kim B, Moon DS, Kwack YS, Hong M, Bahn GH. A report on the Korean Academy of Child and Adolescent Psychiatry vision 2033 survey. J Korean Acad Child Adolesc Psychiatry 2014;25:113-120.

2) Korea Citation Index. KCI statistics [cited 2020 Aug 15]. Available from URL: https://www.cdc.go.kr/yhs/home.jsp?id=m03_05.

3) Kim S, Choi BS, Kim B, Kim KM. Co-author networks in Journal of the Korean Academy of Child and Adolescent Psychiatry. J Korean Acad Child Adolesc Psychiatry 2017;28:149-154.

4) Oh DG, Choi SH, Lee YG, Yeo JS, Lee JG. A study on the operation method for the internationalization of the academic journal. Journal of Korean Library and Information Science Society 2014;45: 159-178.

5) National Information Standards Organization. [cited 2020 Aug 10]. Available from URL: https://www.niso.org/.

6) International Committee of Medical Journal Editors. Recommendations [cited 2020 Aug 5]. Available from URL: http://www.icmje. org/recommendations/.

7) Huh S. Coding practice of the Journal Article Tag Suite extensible markup language. Sci Ed 2014;1:105-112.

8) Huh S. Journal Article Tag Suite 1.0: National Information Standards Organization standard of journal extensible markup language. Sci Ed 2014;1:99-104.

9) Clarivate. Web of Science Group Korea notice 2020 [cited 2020 Aug 10]. Available from URL: http://clarivate.co.kr/category/productrelease/SCIretirement.

10) Clarivate Web of Science. Web of Science: emerging sources citation index [cited 2020 Aug 10]. Available from URL: https://clarivate.com/webofsciencegroup/solutions/webofscience-esci/.

11) SCOPUS. Welcome to Scopus preview [cited 2020 Aug 10]. Available from URL: https://www.scopus.com/home.uri.

12) National Library of Medicine. MEDLINE, PubMed, and PMC (PubMed Central): how are they different? [cited 2020 Aug 10]. Available from URL: https://www.nlm.nih.gov/bsd/difference.html.

13) National Digital Science Library. 2019 Reading factor [cited 2020 Aug 10]. Available from URL: http://www.ndsl.kr/ndsl/search/detail/journal/scjrSearchResultDetailUse.do?cn=NJOU00291301.

14) American Academy of Child \& Adolescent Psychiatry. AACAP history [cited 2020 Aug 10]. Available from URL: https://www. aacap.org/AACAP/About_AACAP/AACAP_History.aspx.

15) Martin A. Handoff: editor's annual report-volume 56, 2017. J Am Acad Child Adolesc Psychiatry 2017;56:1113-1117.

16) Remschmidt H, Graham P. 25th anniversary of ECAP: the origins of the journal. Eur Child Adolesc Psychiatry 2017;26:137-138.

17) Scimago Journal \& Country Rank. European Child and Adolescenct Psychiatry [cited 2020 Aug 10]. Available from URL: https:// www.scimagojr.com/journalsearch.php?q=15548\&tip=sid. 